\title{
Penetration of Isavuconazole in Ascites Fluid of Critically Ill Patients
}

\author{
Tobias Lahmer ${ }^{1, *}$, Gonzalo Batres Baires ${ }^{1}$, Roland M. Schmid ${ }^{1}$, Johannes R. Wiessner ${ }^{1}$, Jörg Ulrich ${ }^{1}$, \\ Maximilian Reichert ${ }^{1}$, Wolfgang Huber ${ }^{1}$, Fritz Sörgel ${ }^{2,3}$, Martina Kinzig ${ }^{2}$, Sebastian Rasch ${ }^{1}$ and Ulrich Mayr ${ }^{1}$
}

1 Klinik und Poliklinik für Innere Medizin II, Klinikum rechts der Isar der Technischen Universität München, Ismaningerstrasse 22, 81675 Munich, Germany; Gonzalo.Batres@mri.tum.de (G.B.B.);

Roland.Schmid@mri.tum.de (R.M.S.); Johannes.wiessner@mri.tum.de (J.R.W.); joerg.ulrich@mri.tum.de (J.U.); maximilian.reichert@mri.tum.de (M.R.); wolfgang.huber@mri.tum.de (W.H.); sebastian.rasch@mri.tum.de (S.R.); Ulrich.Mayr@mri.tum.de (U.M.)

2 IBMP-Institute for Biomedical and Pharmaceutical Research, Paul-Ehrlich-Straße 19, 90562 Nürnberg-Heroldsberg, Germany; Fritz.Soergel@ibmp.net (F.S.); martina.kinzig@ibmp.net (M.K.)

3 Faculty of Medicine, Institute of Pharmacology, University Duisburg-Essen, Hufelandstrasse 55, 45122 Essen, Germany

* Correspondence: TobiasLahmer@me.com; Tel.: +49-89-4140-9345; Fax: +49-89-4140-6243

Citation: Lahmer, T.; Batres Baires, G.; Schmid, R.M.; Wiessner, J.R.; Ulrich, J.; Reichert, M.; Huber, W.; Sörgel, F.; Kinzig, M.; Rasch, S.; et al. Penetration of Isavuconazole in Ascites Fluid of Critically Ill Patients. J. Fungi 2021, 7, 376. https://doi.org/ 10.3390/jof7050376

Academic Editor: David S. Perlin

Received: 16 March 2021

Accepted: 10 May 2021

Published: 11 May 2021

Publisher's Note: MDPI stays neutral with regard to jurisdictional claims in published maps and institutional affiliations.

Copyright: (c) 2021 by the authors. Licensee MDPI, Basel, Switzerland. This article is an open access article distributed under the terms and conditions of the Creative Commons Attribution (CC BY) license (https:/ / creativecommons.org/licenses/by/ $4.0 /)$.
Abstract: Fungal peritonitis is a life-threatening condition which is not only difficult to diagnose, but also to treat. Following recent guidelines, echinocandins and azoles are the recommended antimycotics for the management of intra-abdominal Candida spp. infections, with a favor for echinocandins in critically ill patients. However, the new extended spectrum triazole isavuconazole also has a broad spectrum against Candida spp. Data on its target-site penetration are sparse. Therefore, we assessed isavuconazole concentrations and penetration ratios in ascites fluid of critically ill patients. Obtaining of Isavuconazole plasma and ascites fluid levels as well penetration ratios using paracentesis in critically ill patients. Isavuconazole concentrations were quantified in human plasma and ascites by a liquid chromatography/tandem mass spectrometry (LC-MS/MS) method. Isavuconazole concentrations in plasma and ascites fluid were measured in sixteen critically ill patients. Isavuconazol levels in ascites fluid $(1.06 \mu \mathrm{g} / \mathrm{mL})$ were lower than plasma levels $(3.08 \mu \mathrm{g} / \mathrm{mL})$. Penetration ratio was $36 \%$. In two out of sixteen patients, Candida spp., in detail C. glabrata and C. tropicalis, could be isolated. Cmax/MIC Ratio in plasma of 560 for C. glabrata and 2166 for C. tropicalis could be observed. Following our results, isavuconazole penetrates into ascites. Successful treatment in Candida spp. peritonitis depends on pathogen susceptibility.

Keywords: isavuconazole; peritonitis; intra-abdominal infection; fungal peritonitis; ascites

\section{Introduction}

Intra-abdominal candidiasis (IAC) or following fungal peritonitis is poorly understood compared with other fungal infections such as candidemia. Until now, data and studies on the efficacy of treatment options in IAC are scarce and recommendations in current international guidelines mainly address the findings for candidemia as equal for IAC.

In fact, fungal peritonitis is associated with an overall relevant increase in morbidity and mortality [1]. Beyond this, it is associated with tremendous higher mortality rates in special patient groups, e.g., patients with end stage liver disease [2]

Following recent guidelines, echinocandins and azoles are the recommended antimycotics for the management of intra-abdominal Candida spp. infections, with a favor for echinocandins in critically ill patients [3]. Thus, the new extended spectrum triazole isavuconazole has, beside its approval for the treatment of invasive aspergillosis and mucormycosis, also a broad spectrum against Candida spp. [4,5].

Although, there are some data of tissue penetration into tissue (e.g., brain and lungs), these data are mostly based on animal experiments [6,7]. 
However, data assessing tissue penetration of antifungals at infected tissue sites in humans, especially into ascites fluid, are lacking in general, and of isavuconazole in detail.

The aim of this observational study within critically ill patients is to investigate the penetration ratios of isavuconazole into ascites fluid (I) and the effectiveness in case of Candida spp. peritonitis (II).

\section{Materials and Methods}

Between February 2019 and November 2019, paracentesis was performed in sixteen severe neutropenic critically ill patients (age $60 \pm 15$ years; male gender $n=11$ ) with underlying hematological malignancies. The main reason for ICU admission was septic shock caused by pneumonia (APACHE II score $22 \pm 5$; SOFA Score $11 \pm 3$ ) with need for mechanical ventilation, broad spectrum antibiotics and catecholamines in all patients. Seven out of 16 patients needed renal replacement therapy during ICU stay. This leads to a mean ICU stay of $20 \pm 8$ days and a mortality rate of $88 \%$.

This study on critically ill adults with an indication for isavuconazole treatment was approved by the institutional review board of the Technical University of Munich, Germany $(87 / 20 S)$. Written informed consent was obtained by the patient or their legal representatives.

Based on the critical illness combined with temporarily gastroesophageal reflux/mucositis complications, isavuconazole was applicated through central venous catheters as recommended by the manufacturer (For day 1 and 2, $200 \mathrm{mg}$ every eight hours, then $200 \mathrm{mg}$ per day). Blood samples were taken from an arterial line using EDTA vials, then were centrifugated and stored with the ascites samples at $-70{ }^{\circ} \mathrm{C}$.

Isavuconazole concentrations were quantified in human plasma and ascites by a liquid chromatography/tandem mass spectrometry (LC-MS/MS) method using an API 5000 triple quadrupole mass spectrometer (SCIEX, Concord, Ontario, Canada). Fifty $\mu \mathrm{L}$ of each sample was deproteinized with $300 \mu \mathrm{L}$ acetonitrile (containing the internal standard isavuconazol-d4), and subsequently vortex-shaked and centrifuged. The supernatant was further diluted with Milli- $\mathrm{Q}^{\circledR}$ water $(1: 190, v / v)$, and $10 \mu \mathrm{L}$ of each samples were injected into the LC-MS/MS system.

During validation, the linearity for isavuconazole in human plasma could be demonstrated over a calibration range from 0.107 to $9.68 \mu \mathrm{g} / \mathrm{mL}$. The inter-day precision for isavuconazole SQCs in human plasma was $2.2 \%$ at $8.89 \mu \mathrm{g} / \mathrm{mL}, 3.5 \%$ at $4.45 \mu \mathrm{g} / \mathrm{mL}, 5.4 \%$ at $0.737 \mu \mathrm{g} / \mathrm{mL}$, and $7.6 \%$ at $0.147 \mu \mathrm{g} / \mathrm{mL}$. The inter-day accuracy in human plasma ranged from 94.1 to $106.0 \%$. The intra-day-precision of SQC 1 to SQC 4 ranged from 2.3 to $5.7 \%$, and the intra-day accuracy from 93.7 .1 to $99.4 \%$. No interference at the retention time of isavuconazole and the internal standard could be observed in drug free human plasma samples from critical ill patients.

The linearity for isavuconazole in human ascites could be demonstrated over a calibration range from 0.194 to $10.50 \mu \mathrm{g} / \mathrm{mL}$. Since all samples for ascites were analyzed on one day only an intra-day precision was performed. The intra-day precision for isavuconazole SQCs in human ascites was $3.5 \%$ at $10.1 \mu \mathrm{g} / \mathrm{mL}, 30.9 \%$ at $2.07 \mu \mathrm{g} / \mathrm{mL}$ and $6.6 \%$ at $0.696 \mu \mathrm{g} / \mathrm{mL}$. The intra-day accuracy in human ascites ranged from 100.0 to $103.3 \%$. No interference at the retention time of isavuconazole and the internal standard could be observed in drug free human ascites samples from critical ill patients.

For the single samples obtained at paracentesis, the ratio between the concentration in ascites fluid and the plasma level concentration were calculated. Electronic patient files were used to obtain patient information, e.g., baseline characteristics or laboratory parameters.

Typically, the area under the curve (AUC)/MIC ratio is calculated to predict exposure of isavuconazole. Based on our data with only one plasma and ascites level of the antifungal, we calculated instead the Cmax/MIC ratio that expresses effectiveness of isavuconazole.

Although, data with plasma and ascites levels are from different timepoints, we calculated the Cmax/MIC in two affected patients with candida peritonitis to express the effectiveness of isavuconazole. In all other cases, only the penetration ratios were calculated (ascites drug level/plasma drug level). Variation of timepoint of paracentesis 
and sampling is explained by the circumstance that paracentesis was performed irrespective of the study based on the decision made by the treating ICU physician, e.g., of search for specific sepsis focus or other reasons, e.g., intra-abdominal fluid removal during mechanical ventilation problems.

We used IBM SPSS Statistics 25 (SPSS Inc., Chicago, IL, USA) for all statistical analyses in this study. Descriptive data of normally distributed parameters are presented as mean \pm standard deviation and as median and range for non-parametric parameters.

\section{Results}

Paracentesis was performed with a median of 5.5 days (IQR 3.5-10) after starting of isavuconazole treatment in sixteen critically ill patients (see Table 1). Baseline characteristics, timepoint of isavuconazole treatment and of ascites removal, and cumulative dosage are summarized in Table 1. Isavuconazole plasma and ascites fluid levels, and penetration ratios obtained from paracentesis are listed in Table 2. In two out of sixteen patients, Candida spp., in detail C. glabrata and C. tropicalis, could be isolated (see Table 2).

Table 1. Baseline characteristics, timepoint of isavuconazole treatment, timepoint of ascites removal and cumulative dosage, patients with Candida spp. peritonitis are underlined in red.

\begin{tabular}{|c|c|c|c|c|c|c|c|c|}
\hline Patient & Sex & Age & $\begin{array}{c}\text { Main } \\
\text { Diagnosis }\end{array}$ & $\begin{array}{l}\text { Underlying } \\
\text { Immuno- } \\
\text { Suppression }\end{array}$ & $\begin{array}{c}\text { Day(s) of } \\
\text { Isavuconazole } \\
\text { Treatment }\end{array}$ & $\begin{array}{l}\text { Cumulative } \\
\text { Dose (mg) }\end{array}$ & $\begin{array}{c}\text { Day(s) of Paracentesis } \\
\text { after Starting } \\
\text { Isavuconazole Treatment }\end{array}$ & $\begin{array}{c}\text { Time from } \\
\text { Isavuconazole } \\
\text { Infusion (h) }\end{array}$ \\
\hline 1 & M & 37 & NHL & $\mathrm{N} ; \mathrm{CTx}$ & 14 & 3600 & 5 & 8 \\
\hline 2 & $\mathrm{~W}$ & 77 & AML & $\mathrm{N}$; allo-STx & 17 & 4200 & 3 & 4 \\
\hline 3 & M & 54 & MDS & $\mathrm{N} ; \mathrm{CTx}$ & 21 & 5000 & 11 & 14 \\
\hline 4 & M & 77 & NHL & $\mathrm{N} ; \mathrm{CTx}$ & 7 & 2200 & 1 & 9 \\
\hline 5 & M & 53 & MDS & $\mathrm{N}$; CTx & 23 & 5400 & 14 & 2 \\
\hline 6 & $M$ & 70 & ALL & N; allo-STx & 29 & 6600 & 8 & 9 \\
\hline 7 & $\mathrm{M}$ & 52 & AML & $\mathrm{N}$; allo-STx & 30 & 6800 & 15 & 4 \\
\hline 8 & W & 21 & NHL & $\begin{array}{c}\mathrm{N} ; \\
\text { auto-STx }\end{array}$ & 18 & 4400 & 2 & 6 \\
\hline 9 & $M$ & 62 & ALL & $\mathrm{N} ; \mathrm{CTx}$ & 21 & 5000 & 7 & 17 \\
\hline 10 & $\mathrm{M}$ & 75 & MDS & $\mathrm{N} ; \mathrm{CTx}$ & 12 & 3200 & 5 & 8 \\
\hline 11 & $M$ & 54 & AML & $\mathrm{N}$; allo-STx & 18 & 4400 & 3 & 2 \\
\hline 12 & M & 70 & MDS & $\mathrm{N} ; \mathrm{CTX}$ & 28 & 6400 & 4 & 4 \\
\hline 13 & W & 64 & AML & $\mathrm{N} ; \mathrm{CTx}$ & 14 & 3600 & 9 & 12 \\
\hline 14 & $\mathrm{~W}$ & 68 & NHL & $\begin{array}{c}\mathrm{N} ; \\
\text { auto-STx }\end{array}$ & 13 & 3400 & 6 & 8 \\
\hline 15 & $\mathrm{M}$ & 71 & MDS & $\mathrm{N} ; \mathrm{CTx}$ & 18 & 4400 & 14 & 16 \\
\hline 16 & $\mathrm{~W}$ & 56 & NHL & $\mathrm{N} ; \mathrm{CTx}$ & 15 & 3800 & 4 & 3 \\
\hline
\end{tabular}

NHL = non hodgkin lymphoma; AML = acute myeloid leukaemia; MDS = myelodysplastic syndrome; ALL = acute lymphoid leukaemia; allo-Stx = allogenic stem cell transplantation; auto-STx = autologous stem cell transplantation; $\mathrm{N}=\mathrm{neutropenia}$; CTx = chemotherapy Patients with IAC underlined in red.

Isavuconazole levels in ascites fluid ( 0.36 to $2.71 \mu \mathrm{g} / \mathrm{mL})$ were lower than simultaneous levels in plasma $(0.48$ to $11.49 \mu \mathrm{g} / \mathrm{mL})$ (Table 2$)$. The penetration ratio in the removed ascites fluid (mean $3.1 \pm 0.7 \mathrm{~L}$ ) was $36 \%$ with a high variation of 13 to $63 \%$ in all investigated patients.

In the two patients with isolated Candida spp. from ascites fluid a Cmax/MIC Ratio in plasma of 560 for C. glabrata and 2166 for C. tropicalis could be observed. Ascites values and penetration ratio are presented in Table 2 . The microbiological examinations of the 
ascites fluid of the other patients were all negative.

The initial elevated WBC cell count in ascites from $4.5 \mathrm{G} / 1$ (Patient 1 ) and $1.99 \mathrm{G} / 1$ (Patient 2) decreased $48 \mathrm{~h}$ later to $1.94 \mathrm{G} / 1$ (Patient 1) and $0.45 \mathrm{G} / 1$ (Patient 2), respectively.

Table 2. Isavuconazole concentrations in plasma and ascites fluid, penetration rates and Cmax/MIC ratios.

\begin{tabular}{|c|c|c|c|}
\hline & $\begin{array}{l}\text { All Patients } \\
\quad(n=16)\end{array}$ & $\begin{array}{l}\text { Patient } 1 \\
\text { (C. glabrata } \\
\text { MIC 0.005) }\end{array}$ & $\begin{array}{c}\text { Patient } 2 \\
\text { (C. tropicalis } \\
\text { MIC 0.0012) }\end{array}$ \\
\hline \multicolumn{4}{|l|}{ Isavuconazole } \\
\hline \multirow{2}{*}{\multicolumn{4}{|c|}{$\begin{array}{l}\text { Concentration: } \\
\text { (mean, range) }\end{array}$}} \\
\hline & & & \\
\hline $\begin{array}{l}\text { Plasma } \\
(\mu \mathrm{g} / \mathrm{mL})\end{array}$ & $\begin{array}{l}3.08 \pm 2.56 \\
(0.48-11.49)\end{array}$ & 2.8 & 2.6 \\
\hline $\begin{array}{c}(\mu \mathrm{g} / \mathrm{mL}) \\
\text { Ascites fluid }\end{array}$ & $\begin{array}{c}(0.48-11.49) \\
1.06+0.65\end{array}$ & & \\
\hline$(\mu \mathrm{g} / \mathrm{mL})$ & $\begin{array}{l}1.00 \pm 0.65 \\
(0.36-2.71)\end{array}$ & 0.75 & 1.4 \\
\hline $\begin{array}{c}\text { Penetration ratio } \\
\text { (Ascites drug level/Plasma drug level) (\%) }\end{array}$ & $\begin{array}{l}0.36 \pm 0.15 \\
(0.13-0.63)\end{array}$ & 0.26 & 0.53 \\
\hline $\begin{array}{c}\text { Cmax/MIC Ratio Plasma } \\
\text { Guideline * } \\
(2 \mu \mathrm{g} / \mathrm{mL})\end{array}$ & & 400 & 1666 \\
\hline $\begin{array}{c}\text { Cmax/MIC Ratio } \\
\text { Plasma * } \\
\text { In house }\end{array}$ & & 560 & 2166 \\
\hline
\end{tabular}

${ }^{*}$ Following the total Cmax/MIC ratios as presented above for our in-house MICs, the results are in line with guideline (Cmax/MIC ratio calculated with isavuconazole levels of previous studies) and comparable to EUCAST MIC's $[3,6]$.

\section{Discussion}

Understanding the tissue penetration of systemically administered antifungal agents is crucial for antifungal efficacy in patients with intraabdominal candida infections.

Following the total Cmax/MIC ratios as presented above for our in-house MICs, the results are in line with isavuconazole levels of previous studies and comparable to EUCAST MIC's $[3,6]$. Thus, the in vitro MICs exceed isavuconazole concentrations in plasma. However, the relevance of in vitro MICs for different tissues, e.g., ascites fluid are still unknown and at the moment not available [8].

Echinocandines are still the mainstay for the management of intra-abdominal Candida spp. infections, especially in critically ill patients [1,3,9].

Data on antifungal drug ascites fluid concentrations are limited and typically derived from peritoneal dialysis or surgical patients. [8].

Some data are available for Flucytosine and Fluconazole, which presented comparable plasma and peritoneal levels ( $85 \%$ in patients with Fluconazole) [10,11]. Intraperitoneal voriconazole levels reaching approximately $50 \%$ of plasma levels after oral administration [9]. The peritoneal concentrations of (liposomal) amphotericin B are variable, and have less than $50 \%$ of serum concentrations, and in some cases are undetectable [10,12].

The mean penetration ratio into ascites fluid in this study was $36 \%$ as compared to plasma isavuconazole concentrations with a high variation of $13-63 \%$.

Isavuconazole develops from the water soluble prodrug isavuconazonium and is highly protein bound ( $>99 \%)$, predominantly, to albumin, and has a large apparent volume of distribution (300-500 L) [13]. Thus, following the results from the study of Lee et al. with oral administrated radiolabeled isavuconazonium sulfate in rats, detectable radioactivity could be found within $1 \mathrm{~h}$ post dose in 56/65 examined tissues/fluids [6]. However, no data were available for ascites or peritoneal fluid [6].

The reason for different penetration rates might either be the fact that isavuconazole is not only bound to albumin, but also to other serum components, or a different binding potency of albumin in the presence of serum that might by influenced by critically 
ill circumstances, e.g., $\mathrm{pH}$ abnormalities and also based on different albumin levels in ascites fluid.

Although, we see the strength of our results our study has several limitations: First, the study is conducted as a single center study, second the study has an observational character without interventions and a small sample size and third variation of our measured isavuconazole levels may be based on the fact that timepoints of drug monitoring were not standardized in this study.

\section{Conclusions}

In summary, the results of this study suggest that isavuconazole has a varied penetration into the ascitic fluid. However, overall success of treatment with isavuconazole in cases of Candida peritonitis depends on the interplay of susceptibility of the isolated species, the immune status of the host, and possibly other inter-related factors, which have to be investigated in further clinical studies.

Author Contributions: Conceptualization, U.M. and T.L., Methodology, T.L., U.M., and S.R., Software: T.L., Validation: T.L., F.S., M.K. and U.M., Analysis: T.L. and U.M., Investigation: G.B.B., R.M.S., J.R.W., J.U., M.R., S.R. and W.H., Resources: T.L., U.M., S.R., M.K. and F.S. All authors have read and agreed to the published version of the manuscript.

Funding: This research received no external funding.

Institutional Review Board Statement: The Ethics Committee of the Technical University of Munich approved the protocol of this retrospective study and waived the need to obtain consent for the collection, analysis, and publication of the data (approval 87/20S; 04/2020).

Informed Consent Statement: Informed consent was obtained from all subjects involved in the study.

Data Availability Statement: All relevant data are made available in the manuscript.

Conflicts of Interest: T.L. received travel grants and lecture fees from Pfizer and Gilead. The other authors declare that they have no conflict of interest.

\section{References}

1. Dupont, H.; Massias, L.; Jung, B.; Ammenouche, N.; Montravers, P. Pharmacokinetic study of anidulafungin in ICU patients with intra-abdominal candidiasis. J. Antimicrob. Chemother. 2017, 72, 1429-1432. [CrossRef] [PubMed]

2. Lahmer, T.; Brandl, A.; Rasch, S.; Schmid, R.M.; Huber, W. Fungal Peritonitis: Underestimated Disease in Critically Ill Patients with Liver Cirrhosis and Spontaneous Peritonitis. PLoS ONE 2016, 11, e0158389. [CrossRef] [PubMed]

3. Pappas, P.G.; Kauffman, C.A.; Andes, D.R.; Clancy, C.J.; Marr, K.A.; Ostrosky-Zeichner, L.; Reboli, A.C.; Schuster, M.G.; Vazquez, J.A.; Walsh, T.J.; et al. Clinical Practice Guideline for the Management of Candidiasis: 2016 Update by the Infectious Diseases Society of America. Clin. Infect. Dis. 2016, 62, e1-e50. [CrossRef] [PubMed]

4. Maertens, J.A.; Raad, I.I.; Marr, K.A. Isavuconazole vs. voriconazole for the primary treatment of invasive mould disease caused by Aspergillus and other filamentous fungi (SECURE): A pahse 3, randomised-controlled, non- inferiority trial. Lancet 2016, 387, 760-769. [CrossRef]

5. $\quad$ Denis, J.; Ledoux, M.P.; Nivoix, Y.; Herbrecht, R. Isavuconazole: A new broad-spectrum azole. Part 1: In vitro activity. J. Mycol. Med. 2018, 28, 8-14. [CrossRef] [PubMed]

6. Lee, A.; Prideaux, B.; Lee, M.H.; Zimmerman, M.; Dolgov, E.; Perlin, D.S.; Zhao, Y. Tissue Distribution and Penetration of Isavuconazole at the Site of Infection in Experimental Invasive Aspergillosis in Mice with Underlying Chronic Granulomatous Disease. Antimicrob. Agents Chemother. 2019, 63, e0524-19. [CrossRef] [PubMed]

7. Rouzaud, C.; Jullien, V.; Herbrecht, A.; Palmier, B.; Lapusan, S.; Morgand, M.; Guéry, R.; Dureault, A.; Danion, F.; Puget, S.; et al. Isavuconazole Diffusion in Infected Human Brain. Antimicrob. Agents Chemother. 2019, 63, e02474-18. [CrossRef] [PubMed]

8. Jørgensen, K.M.; Astvad, K.M.T.; Hare, R.K.; Arendrup, M.C. EUCAST Susceptibility Testing of Isavuconazole: MIC Data for Contemporary Clinical Mold and Yeast Isolates. Antimicrob. Agents Chemother. 2019, 63, e00073-19. [CrossRef] [PubMed]

9. Kullberg, B.J.; Viscoli, C.; Pappas, P.G.; Vazquez, J.; Ostrosky-Zeichner, L.; Rotstein, C.; Sobel, J.D.; Herbrecht, R.; Rahav, G.; Jaruratanasirikul, S.; et al. Isavuconazole Versus Caspofungin in the Treatment of Candidemia and Other Invasive Candida Infections: The ACTIVE Trial. Clin. Infect. Dis. 2019, 68, 1981-1989. [CrossRef] [PubMed]

10. Felton, T.; Troke, P.F.; Hope, W.W. Tissue penetration of antifungal agents. Clin. Microbiol. Rev. 2014, 27, 68-88. [CrossRef] [PubMed] 
11. Pea, F.; Righi, E.; Cojutti, P.; Carnelutti, A.; Baccarani, U.; Soardo, G.; Bassetti, M. Intra-abdominal penetration and pharmacodynamic exposure to fluconazole in three liver transplant patients with deep-seated candidiasis. J. Antimicrob. Chemother. 2014, 69, 2585-2586. [CrossRef] [PubMed]

12. Bellmann, R.; Smuszkiewicz, P. Pharmacokinetics of antifungal drugs: Practical implications for optimized treatment of patients. Infection 2017, 45, 737-779. [CrossRef] [PubMed]

13. Ledoux, M.P.; Denis, J.; Nivoix, Y.; Herbrecht, R. Isavuconazole: A new broad-spectrum azole. Part 2: Pharmacokinetics and clinical activity. J. Mycol. Med. 2018, 28, 15-22. [CrossRef] [PubMed] 